\title{
Death Studies
}

Sense of Presence and Meaning-Making

E. Steffen \& A. Coyle

\section{SENSE OF PRESENCE EXPERIENCES \\ AND MEANING-MAKING IN BEREAVEMENT: A QUALITATIVE ANALYSIS}

\section{EDITH STEFFEN ${ }^{1}$ and ADRIAN COYLE}

Department of Psychology, University of Surrey, United Kingdom

Keywords: bereavement; continuing bonds; meaning-making; post-traumatic growth; sense of presence; spirituality

Acknowledgements: We would like to extend our sincere thanks to two anonymous reviewers and to Robert A. Neimeyer and Nigel Field for their invaluable and insightful advice and support in helping us to develop this article for publication. 


\section{SENSE OF PRESENCE EXPERIENCES}

\section{AND MEANING-MAKING IN BEREAVEMENT:}

\section{A QUALITATIVE ANALYSIS}

This qualitative study aimed to explore the potential role that might be played by reported experience of 'sensing the presence of the deceased' in meaning-making processes in bereavement. Semi-structured interviews were conducted with twelve participants who reported having had such an experience and the transcripts were subjected to thematic analysis. Seven overarching themes were identified, three of which were considered central: 'finding benefit in the continuation of the deceased', 'finding benefit in the continued relationship', and 'finding meaning through existential, spiritual, and religious sense-making'. While participants found many benefits in what they experienced, finding meaning beyond immediate coping seemed to require the availability of spiritual/religious frameworks which could be adopted or, if available but discrepant, could meaningfully accommodate the experience.

Keywords: bereavement; continuing bonds; meaning-making; post-traumatic growth; sense of presence; spirituality

Bereavement has been described as a major life crisis with potentially severe effects on the survivor's physical and psychological well-being (Lindemann, 1944; Parkes, 1970, 1996). For much of the twentieth century, Western approaches to bereavement have emphasized emotional disengagement from the deceased and the 'working-through' of grief (Freud, 
1917). Following increasing challenges to this 'grief work' paradigm (e.g. Wortman \& Silver, 1989), a new strand of bereavement research has started to identify positive effects of bereavement under the categories of coping (e.g. Folkman, 2001) and post-traumatic growth (Calhoun \& Tedeschi, 2006).

Linking bereavement research with research into post-traumatic cognitive processes has drawn attention to the significance of post-bereavement 'meaning-making'. According to Janoff-Bulman (1992), major trauma can shatter people's 'assumptive world' with regard to core beliefs about the benevolence and meaningfulness of the world and one's self-worth. Such 'existential trauma' (Benore \& Park, 2004) can lead to a 'search for meaning' (Frankl, $1959 ;$, with the goal of integrating the loss into the assumptive worldview or 'self-narrative' (Neimeyer, 2001) through meaning reconstruction processes such as sense-making, benefitfinding, and identity change (Neimeyer, 2006).

Religious and spiritual beliefs can aid these processes (Davis, Nolen-Hoeksema \& Larson, 1998), and the potentially positive role of religion in bereavement has been observed (e.g. Becker et al., 2007; Golsworthy \& Coyle, 1999; Wortman \& Park, 2008). However, a major loss can also challenge existing religious beliefs or lead to a (re-)discovery of faith and spiritual change (Balk, 1999). Spiritual experiences in bereavement may play a significant role here. Benore and Park (2004) suggest, for example, that the frequently reported experience of sensing the presence of the deceased can have a facilitative function in postloss meaning-making, as the belief in a continued attachment with the deceased may constitute a 'death-specific religious belief', influencing the survivor's appraisal of the loss and death in general. It is these sense-of-presence experiences that constitute the focus of the research reported in this paper.

Sense-of-presence experiences can be defined as the nonmaterial quasi-sensory subjective but (experienced as) veridical 'feeling of presence' of the deceased (Bennett \& 
Bennett, 2000; Datson \& Marwit, 1997) which tends to occur unexpectedly (e.g. Conant, 1996) and is generally perceived as 'comforting' (e.g. Parkes, 1970; Sormanti \& August, 1997), 'pleasant' (Grimby, 1998;), and helpful or positive (e.g. Chan et al., 2005; LaGrand, 1997). Sometimes, though, sense-of-presence experiences are perceived as negative; for example, Tyson-Rawson (1996) noted that an 'unwelcome' or 'intrusive presence' is often linked with 'unfinished business' in the relationship with the deceased. Although the reported percentages of negative experiences are small compared to positive ones, e.g. $6 \%$ and $69 \%$ respectively by Rees $(1971,2001)$ and $14 \%$ and $86 \%$ respectively by Datson and Marwit (1997), distress arising from such an experience could potentially be significant.

As regards the general implications of this experience for well-being following bereavement, clinical benefits for the bereaved have been observed (e.g. Rees, 2001; Richards, Acree \& Folkman, 1999), although some research has also indicated correlations with higher levels of bereavement-related distress (Simon-Buller, Christophersen \& Jones, 1988-89), depending on the cultural context (Lalande \& Bonanno, 2006) or the intensity of the experience (Lindstrom, 1995). While sense-of-presence experiences have often been described as 'hallucinations' or 'illusions' resulting from denial or 'searching behavior' (e.g. Bowlby, 1998; Field, 2008; Parkes, 1970, 1996), they have been found to be not necessarily maladaptive (e.g. Datson \& Marwit, 1997; Epstein, Kalusz \& Berger, 2006; Grimby, 1998). However, a recent study by Field and Filanosky (2010) found an association between reported sensory perceptions of a clearly visual, auditory or tactile nature and two factors linked with increased risk of clinically significant and enduring distress following bereavement, i.e. violent death and responsibility for the death, whereas more 'internalized expressions' of the continuing relationship with the deceased were positively associated with growth. The authors suggested that the more concrete perceptions could be thought of as intrusive, PTSD-type experiences, possibly indicating a lack of integration and positive 
meaning reconstruction. Neimeyer, Baldwin, and Gillies (2006) similarly found that a stronger continuing relationship with the deceased was associated with more intense grief, although this effect was moderated significantly by people's ability to make sense of the loss, stressing again the importance of meaning-making following bereavement.

It has been observed that meaning-making with regard to presence-sensing is greatly influenced by the bereaved person's cultural context (e.g. Walter, 2002). In the West, for example, there is a well-documented reluctance among perceivers to disclose its occurrence for fear of ridicule (Rees, 2001), having it 'explained away' (Parker, 2005), or being thought of as 'mad or stupid' (Hay \& Heald, 1987). Building on cross-cultural findings (e.g. Yamamoto, Okonogi, Iwasaki \& Yoshimura, 1969), the 'continuing bonds' perspective (Klass, Silverman \& Nickman, 1996) has shown that such experiences can be seen as normal events within the ongoing relationship with the deceased and can be conceptualized within spiritual and religious frameworks. This may be more difficult in a Western context, challenging traditional assumptions about the duality of the material and non-material worlds (Bennett \& Bennett, 2000) and life and death (Rosenblatt, 1997). Additionally, they challenge many religious understandings regarding the possibility of post-death interaction (Klass \& Goss, 1999; Walter, 2002). ${ }^{1}$

In a recent review of the literature, it was suggested that socially sanctioned conceptual frameworks need to be available for the meaningful integration of these experiences and the possible occurrence of post-traumatic growth (Steffen \& Coyle, 2010). Due to the 'privatisation of grief' (Walter, 1999), counseling and therapy are often the only places where meaning-making is actively engaged in following bereavement. However, most bereavement counseling is still located within a 'breaking bonds' paradigm (Stroebe, Gergen, Gergen \& Stroebe, 1996), with potentially negative effects for some, as demonstrated by Taylor (2005), who found that clients with sense-of-presence experiences often felt a lack of 
acceptance from counselors. Much research into sense-of-presence experiences has been concerned with the incidence and correlates of the experience and its potential impact on measures of bereavement-related distress and adjustment. The present study builds on the literature discussed above to explore what role(s), if any, sense-of-presence experiences might play in meaning-making processes following bereavement, taking (the lack of) available conceptual frameworks into account. More specifically, the study considers how sense-of-presence experiences are conceptualized and made sense of by those who report them and how, if at all, sense-of-presence experiences are perceived to have affected their assumptive worldviews. As the study is concerned with gaining insight into the subjective experience of presence-sensing and related meaning-making processes, a phenomenologically-oriented qualitative research approach, with its emphasis on participants' lifeworlds and sense-making, is appropriate. While some qualitative research has addressed presence-sensing (e.g. Conant, 1996; Sanger, 2009), there is a lack of research that has focused specifically on its potential role in bereavement-related meaning-making (see Parker, 2005, for an exception).

\section{Method}

\section{Participants}

The study recruited participants from the general population rather than specifically religious people to ensure openness to varieties of meaning-making. Inclusion criteria were for participants to have had at least one 'sense of presence' experience and to have been bereaved for at least 18 months to allow for some processing of the loss to have occurred. After obtaining ethical approval, 38 non-religious community groups in south-east England were contacted and asked to forward information about the study to members. Participants 
were also recruited through word of mouth and 'snowballing'. The appropriateness of participating was assessed individually for each volunteer using a telephone screening procedure. Ultimately 12 participants were included. The sample consisted of ten women and two men, with a mean age of 49.5 years (range $30-80 ; \mathrm{SD}=15.8$ ). Eight participants described themselves as 'White British', three as 'Other White', and one as 'White Irish'. Eight had been educated to degree and postgraduate degree level, two to diploma level and two held school certificates. As regards their religion and/or spirituality, seven participants identified themselves as Christian and five reported belonging to no religious body. Five rated religion and/or spirituality as 'extremely' important in their lives, five as 'very' important, one as 'quite', and one as 'not at all' important.

\section{Interview Schedule and Data Collection Procedure}

Data were generated using semi-structured interviews lasting between one and two hours. The interview schedule contained open-ended questions to allow participants to describe their experiences and what they meant to them as freely as possible while exploring a range of potentially significant dimensions as suggested by relevant theory and research, e.g. how presence-sensing might impact on the survivors' relationships with the deceased and others, their sense-making regarding the death, their belief systems, and sense of self. General questions were supported by prompts and probes to access deeper levels of meaning. The interview schedule was, however, applied flexibly so that relevant unexpected avenues could be explored.

Prior to the interviews, participants were given information outlining the study's purpose and procedure. The interviews took place at a university or in participants' homes; two were conducted by telephone at the participants' request. The interviews were digitally 
recorded and transcribed orthographically. Identifying details were removed and pseudonyms were assigned.

\section{Analytic Procedure}

Transcripts were subjected to thematic analysis in accordance with Braun and Clarke's (2006) guidelines. These authors suggested that researchers using thematic analysis should

elaborate their analytic stance by making transparent decisions about a study's theoretical and epistemological commitments and depth of analysis. Specifically, on an epistemological continuum between the extremes of 'naïve realism' and radical constructionism (Madill, Jordan, \& Shirley, 2000), the present study is positioned near the middle, close to a contextual-constructionist stance. This stance posits that participants' meanings are partially accessible through analysis, although requiring interpretation, and that the research process is co-constructed and embedded within a cultural and historical context. This study not only acknowledges that the researcher is necessarily affected by pre-existing theoretical and personal understandings, it also seeks to employ relevant theory actively and transparently to deepen the analysis, albeit with the analysis informed rather than driven by theory.

The analytic procedure followed Braun and Clarke's (2006) six-phase outline of thematic analysis. Transcripts were read attentively and the entire data set was coded. Codes were grouped meaningfully under initial themes and data extracts were collated accordingly. Overarching themes were developed and discussed, followed by repeated reviewing of themes and sub-themes. A general description across cases was developed and key themes were then analyzed in detail and at greater interpretative depth. Theoretical constructs describing meaning-making processes were incorporated where evidenced within the data. 


\section{Evaluation of the Study}

As in all qualitative analysis requiring subjective engagement, the aim is to produce a credible reading rather than a definitive one. The themes identified were the authors' readings, with the first author taking the lead in checking themes against data repeatedly to ensure they were grounded in and evidenced by the data, followed by repeated checking of codes and themes with the second author. Following completion of the analysis, a summary of the findings was sent to participants and it was ascertained through their feedback that the findings accorded with their own interpretation of their experiences. The findings were also evaluated by three independent reviewers during the publication process, which constituted an additional credibility check. Furthermore, evaluative criteria for qualitative research suggested by Elliott et al. (1999) and Yardley (2000) can be applied to the analysis (including transparency, rigor, coherence, and sensitivity to context).

\section{Analysis}

Participants reported a variety of sense-of-presence experiences (see Table 1). Some reported having had only one such experience, sometimes early in their bereavement, sometimes years after the loss. Some participants reported several such experiences and some reported ongoing and regular sensing experiences, even years after the loss.

Table 1. Overview of participants' main reported sense-of-presence experiences

\begin{tabular}{|l|l|l|l|}
\hline Participant & $\begin{array}{l}\text { Main person } \\
\text { sensed }\end{array}$ & $\begin{array}{l}\text { Main reported perceptual features of the sense-of- } \\
\text { presence experience }\end{array}$ & $\begin{array}{l}\text { Other people } \\
\text { sensed }\end{array}$ \\
\hline Antonia & Son & tingling, feeling the deceased is close by & $\begin{array}{l}\text { Husband } \\
\text { Father }\end{array}$ \\
\hline Bridget & Father & hearing the voice of the deceased, feeling caressed & Sister \\
\hline Catrin & Husband & feeling held & Father \\
\hline Elaine & Grandmother & feeling her hair is stroked, feeling the deceased is in & \\
\hline
\end{tabular}




\begin{tabular}{|l|l|l|l|}
\hline & & the room & \\
\hline Gillian & Father & $\begin{array}{l}\text { seeing the hands of the deceased on her steering } \\
\text { wheel }\end{array}$ & Mother \\
\hline Harriet & Grandmother & feeling the deceased is standing close by & \\
\hline Kathy & Teacher/mentor & $\begin{array}{l}\text { tunnel of light dream at time of death, feeling the } \\
\text { deceased is standing close by, hearing the voice of } \\
\text { the deceased }\end{array}$ & Grandfather \\
\hline Nicholas & Mother & $\begin{array}{l}\text { feeling the deceased is walking alongside, hearing the } \\
\text { voice of the deceased }\end{array}$ & \\
\hline Robert & Grandmother & feeling the deceased is around & $\begin{array}{l}\text { Grandfather } \\
\text { Father }\end{array}$ \\
\hline Shirley & Father & seeing the deceased stand by her bed & \\
\hline Tanya & Grandfather & $\begin{array}{l}\text { smelling the tobacco of the deceased, feeling the } \\
\text { deceased is in the back of the car }\end{array}$ & \\
\hline Yvonne & Grandmother & seeing the deceased stand at the bottom of her bed & \\
\hline
\end{tabular}

Seven themes (and constituent sub-themes) were identified across the data set (see Table 2), although the data covered a broad range of aspects relating to bereavement and the focal experience and varied considerably across individuals, for example in terms of the form and context of the reported experiences.. Before focusing on some of these themes in greater detail, an overview of all themes and sub-themes is given below. When quoting participants, ellipsis points (...) indicate pauses in the flow of speech; empty square brackets indicate that material has been omitted.

Table 2. Themes and sub-themes

\begin{tabular}{|c|c|}
\hline Themes & Sub-themes \\
\hline $\begin{array}{l}\text { 1. A natural feeling of the extraordinary } \\
\text { 'It wasn't a physical thing. I didn't feel anything } \\
\text { physically. But I felt it so strongly. I felt him.' } \\
\text { (Catrin) }\end{array}$ & $\begin{array}{l}\text { a) Near-sensory awareness } \\
\text { b) Intuitive knowing } \\
\text { c) A different kind of reality } \\
\text { d) The experience feels natural }\end{array}$ \\
\hline $\begin{array}{l}\text { 2. Finding benefit in the continuation of } \\
\text { the deceased } \\
\text { 'It's wonderful. It's a gift. Grateful. It feels } \\
\text { wonderful, because um yeah, they're still here.' } \\
\text { (Antonia) }\end{array}$ & $\begin{array}{l}\text { a) The deceased is still the same } \\
\text { b) The deceased is not completely lost } \\
\text { c) Emotional benefits } \\
\text { d) Practical support } \\
\text { e) Viewing the deceased as a spiritual } \\
\text { being and resource }\end{array}$ \\
\hline $\begin{array}{l}\text { 3. Finding benefit in the continued } \\
\text { relationship }\end{array}$ & $\begin{array}{l}\text { a) Confirmation of the continuing bond } \\
\text { b) Mutuality of the relationship }\end{array}$ \\
\hline
\end{tabular}




\begin{tabular}{|c|c|}
\hline $\begin{array}{l}\text { '...it just felt quite intimate and connected really.' } \\
\text { (Kathy) }\end{array}$ & c) Affirmation of self in relationship \\
\hline $\begin{array}{l}\text { 4. Finding meaning through existential, } \\
\text { spiritual, and religious sense-making } \\
\text { 'They kind of give me, I suppose, a faith that } \\
\text { there is more than just this one life, you know...' } \\
\text { (Bridget) }\end{array}$ & $\begin{array}{l}\text { a) Belief in life after death } \\
\text { b) Death as temporary separation } \\
\text { c) Existential insight } \\
\text { d) Spiritual and religious meaningfulness } \\
\text { e) Spiritual and religious growth }\end{array}$ \\
\hline $\begin{array}{l}\text { 5. Negotiation of the conceptual status of } \\
\text { the experience } \\
\text { 'I'm quite cynical about a whole lot of stuff like } \\
\text { that, but the fact that that had happened and that I } \\
\text { felt that and that I've sensed that [ ] I think, got to } \\
\text { be something in that.' (Elaine) }\end{array}$ & $\begin{array}{l}\text { a) Conflict between experience and } \\
\text { explanations } \\
\text { b) Acknowledgement and dismissal of } \\
\text { alternative explanations } \\
\text { c) Personal experience as most convincing } \\
\text { d) Resolving the conflict } \\
\text { e) Acknowledging involvement of mind }\end{array}$ \\
\hline $\begin{array}{l}\text { 6. Importance of realness } \\
\text { 'You know, it wasn't like a shadow or anything. } \\
\text { She was literally there at the bottom of my bed.' } \\
\text { (Yvonne) }\end{array}$ & $\begin{array}{l}\text { a) Sense of reality } \\
\text { b) The experience as coming from outside } \\
\text { c) Trustworthiness of perceiver } \\
\text { d) Confirmation by others } \\
\text { e) Factual account }\end{array}$ \\
\hline $\begin{array}{l}\text { 7. Lack of social acceptance } \\
\text { 'When you ask people, tell people and they say } \\
\text { oddly, "No...", you think "Oh God. Perhaps I was } \\
\text { imagining it then."' (Shirley) }\end{array}$ & $\begin{array}{l}\text { a) Difficulty sharing the experience } \\
\text { b) Meeting with conflict } \\
\text { c) Social acceptance as exception }\end{array}$ \\
\hline
\end{tabular}

The participants' sense of having had an extraordinary experience by perceiving the actual near-physical presence of their deceased loved ones was central to all accounts. The first theme, 'A natural feeling of the extraordinary', describes the reported perceptual quality of the experience: there is a sense that the deceased loved one is temporarily present in an almost physical form, perceived partly through near-sensory awareness and partly through an equally veridical intuitive knowing. While most participants felt they were somehow in touch with a different kind of reality, many reported they experienced this as normal (the experience feels natural).

The feeling that the deceased loved one somehow continued to exist was associated with gains for the bereaved, as expressed in the theme 'Finding benefit in the continuation of the deceased'. All participants noted the continuity between the loved one before and after 
death (the deceased is still the same), which enabled them to feel that the deceased is not completely lost. This was accompanied by emotional benefits. Another benefit included the sense that the deceased provided practical support with survivors' ongoing lives. Additionally, many found they could approach the deceased as a spiritual being with supernatural features (viewing the deceased as a spiritual being and resource).

A similar theme was that of 'Finding benefit in the continued relationship'. Almost all participants interpreted the sense-of-presence experience as an expression and proof of their ongoing relationship with the deceased (confirmation of the continuing bond). Most also reported experiences of (quasi)communication or interaction that suggested the mutuality of the relationship. Maintaining their role within this continuing bond also seemed to serve as a source for self-definition and self-esteem (affirmation of self in relationship).

Meaning-making with regard to a deeper understanding and purpose could be discerned across cases and is rendered as 'Finding meaning through existential, spiritual, and religious sense-making'. The majority of participants viewed the experience as confirming or promoting the belief in life after death, and several spoke of it as encouraging the hope for reunion (death as temporary separation). For many, sense-of-presence experiences provided insight into ultimate concerns (existential insight), and the majority drew on spiritual and religious frameworks in their sense-making (spiritual and religious meaningfulness). Many also saw the experience as leading to (further) spiritual and religious growth.

Although participants described the experiences as almost exclusively beneficial, the accounts often revealed a struggle with culturally available understandings. The theme 'Negotiation of the conceptual status of the experience' captures the reported discrepancies between participants' felt experience and culturally available explanatory frameworks (conflict between experience and explanations) and the discursive strategies that 
participants employed to resist dominant explanations (acknowledgement and dismissal of alternative explanations). Some participants argued for their personal experience as most convincing, and several suggested a compromise between personal and cultural interpretations (resolving the conflict). Many participants worked up credibility by adopting the dominant discourse (acknowledging involvement of mind) while preserving their claim to veridicality.

The theme 'Importance of realness' was central in terms of the status of the accounts and the described meaning-making processes. Most participants stressed the sense of reality as a core feature of their experiences, and, supporting this claim, the perception of the experience as coming from outside. The credibility of the accounts was often worked up by drawing attention to the trustworthiness of the perceiver, by drawing on experiences and supportive evidence from others (confirmation by others) and through the construction of factual accounts.

The above-mentioned - conscious or unconscious - efforts to construct persuasive accounts of their experiences paralleled the frequently-expressed concern about negative responses from others. The theme 'Lack of social acceptance' could be discerned across all accounts. Many participants talked about difficulty sharing the experience with others and reported meeting with conflict in their social environment, while experiences of understanding and acceptance were mostly reported as exceptional (social acceptance as exception).

Due to the constraints of this paper, only three of the seven themes can be presented in greater detail. The following analysis will concentrate on 'Finding benefit in the continuation of the deceased', 'Finding benefit in the continued relationship', and 'Finding meaning through awareness of an afterlife', as these themes can be considered key with regard to the research aims. Note that in several places two sub-themes from Table 2 have 
been summarized under one section heading, namely 2 a) and b), 2 c) and d), 4 a) and b) and $4 \mathrm{c})$ and d).

\section{Finding Benefit in the Continuation of the Deceased}

Based on the feeling of the actual presence of the deceased, a major theme in the data was the sense of the ongoing existence of the deceased in both identical and changed ways and the benefits arising from this for the bereaved.

The deceased is still the same and not completely lost. Most participants talked about how they made sense of the perceived presence as that of the deceased loved one through the recognition of familiar features. This helped participants integrate the experience into their overall picture of the deceased:

'Afterwards [ ] I thought that was her way of telling me she was all right. Because she wasn't distressed or anything like that. She looked like she always did and she was smiling.' (Yvonne)

'I thought, well, actually, it would make sense for her because not even death can stop her being a mother. Still she's got to look out for her children.' (Nicholas)

The perceived continuity of the loved one's identity therefore not only served as a reminder of the past, allowing for a more complete reconstruction in memory but, importantly, the familiar identity of the deceased was felt to be a living reality in the here and now:

'My father had a wonderful sense of humor. He will come and be felt with a joke usually. It's like he's seen something with me and he just cracks a wonderful one-liner and it's really funny.' (Robert) 
Robert uses the past tense when referring to his father's sense of humor as a known feature of his pre-death character but then acknowledges his father's continuing living presence as recognized through this characteristic in the present tense, indicating a sense of a partial loss reversal or a presence in absence (Goss \& Klass, 2005). Such an understanding was shared by many other participants:

'I don't feel I've completely lost her. I feel somewhere she's there [ ] she's not changed at all. She's just the same person that she was [ ] It's almost like she's there in the background, almost ... just making sure things are kind of OK.' (Elaine)

Elaine seemed to feel that her deceased grandmother was partly restored through the sensing experience, but this did not mean that her death was denied. Rather, Elaine suggested that the essence of her grandmother was unchanged but that the difference lay in the way she was present, as indicated by her use of 'somewhere' and 'almost'.

Emotional benefits and practical support. The partial restoration of the deceased experienced as a result of presence-sensing was said to have been associated with positive emotions. Most of the participants described the experience as 'comforting' and many used the word 'calming'. Some said they felt 'happy' and at 'peace'. Others described it as 'magical' (Nicholas), 'precious' (Harriet) or that 'it meant everything' (Gillian). For Antonia, who talked about coping with the second traumatic loss in her life, such feelings were unusual:

'I was so surprised that I was able to have that sense of joy in the midst of grief that made me smile so widely when I was having this tingling in the car, driving. I knew, I just felt he was next to me.'

The emotional benefits reported here meant the bereaved could focus on the deceased in a way that was not associated with negative affect, restless 'searching behavior' and an inability to turn attention to other activities (e.g. Parkes, 1996). Instead, many of the 
participants described how they felt helped by the deceased when getting on with the demands of their lives:

'When I got into my car after he died, oh, [ ] it was wonderful. I just completely relaxed inside this car and he was saying to me, "Cat, now I can show you how to drive." [ ] He was with me. It was as if he was sitting next to me really.' (Catrin)

Shirley similarly felt helped by her deceased husband, as she felt she was able to find a lost object 'as a result of what I thought was an answer from him'. In some cases, the help from the deceased was felt to be life-changing. For example, Kathy described how she experienced the presence of her deceased teacher/mentor when first chancing upon a book in an area she later developed as a specialty:

'I just had this sense, and it felt like it was from her, just going, "This is it." [ ] It just felt like it was her. I took it to mean it was her saying, "Pay attention. This is important." And "This is why we were connected." [ ] So when I picked up the first book, it was almost like she was, she had intended that to be there.'

This quotation demonstrates the inter-relatedness of presence sensing and meaningmaking. The initially ineffable experience ('I just had this sense') of a quasi-communicated message from the deceased ('like it was from her') could be understood in terms of the identity of the deceased (in this case, teacher) and the relationship with the deceased ('why we were connected'), leading to a sense of being guided in meaningful life choices. While the meaning-making part could be seen as retrospective attribution, it could also be viewed as a translation of the initial sense, an 'unpacking' of its implicational meaning.

Viewing the deceased as a spiritual being and resource. For many participants, experiencing the presence as supportive was connected with viewing the deceased as a spiritual being with supernatural powers. For example, Elaine felt that her deceased grandmother was helpfully involved when she survived a life-threatening event: 
'Well, they say that everyone's got a guardian angel and I think she's mine. Literally within three hours I walked out of the hospital and I had my speech back. I had all my movement back.'

Even when participants did not frame the status of the deceased in explicitly spiritual terms, such a connection was sometimes implied, for example when the deceased could be located in a higher realm, as when Yvonne spoke of the deceased as 'looking down', or Gillian as 'watching over me'. This can be seen as a positive example of 'relocation' (Stroebe, Schut \& Stroebe, 2005), i.e. the integration of the understanding of the deceased as still present albeit not physically. Sometimes, a spiritual or supernatural link was implied by the effect of the actions of the deceased:

'It was such a clear sense of "I have been forgiven. She has forgiven me." And [the guilt] was gone. It was really gone [ ] because of somehow what she was. That's how it was possible.' (Harriet)

The configuration of the deceased as being somehow imbued with spiritual or supernatural powers meant that the deceased could bestow benefits not just despite their death but by virtue of their death or spiritual status. Some responded to the deceased as such a resource by turning to them for help:

'And so when there have been challenges that [family members] have faced, I have prayed to my mother [ ] and I don't know whether I would have done that if I hadn't had this experiential sense of her continuing in an active way.' (Nicholas)

While most participants did not use expressions such as 'praying', analogous communicative stances were often reported. In the present sample, many appeared to have an understanding of the deceased as reconfigured in partly more earthly and partly more supernatural ways and derived benefits from both. 


\section{Finding Benefit in the Continued Relationship}

While the sense of the reconfigured deceased loved one was reported as providing solace, support, and a spiritual resource, most viewed the experiences as forming part of their ongoing although reconfigured relationship with the deceased, in line with classifications in the bereavement literature of sense-of-presence experiences as expressions of a 'continuing bond' with the deceased (e.g. Klass, Silverman \& Nickman, 1996).

Confirmation of the continuing bond. The majority of participants viewed the experience as a temporary sign of a more permanent bond with the deceased, which was partly characterized by a continuity between the pre-death and the post-death relationship. Tanya links the context in which she experienced her grandfather's presence with their shared history:

'When I was little [ ] I'd clean all the chrome for him and I'd wash the car [ ] so I wasn't surprised when I had these experiences in my own car because that was [ ] the connection my grandpa and I had.'

In accordance with findings reported by Silverman and Klass (1996), participants' recognition of continuous features did not imply that maintaining a bond was about 'living in the past' for them. Rather, the bond seemed to involve relational processes that had their roots in the past and carried on into the present. For example:

'There was no end. There was no finishing except of course my longing, yearning to see him and to be with him, but everything, it just carried on, it carried through some kind of veil, a very thin veil.' (Catrin)

Catrin's quotation is an example of how participants noted again how the partly consistent and partly changed nature of the relationship expressed 'presence in absence' rather than a complete recovery or a complete loss of the connection. Catrin conveys this dual 
meaning by describing the simultaneous sense of intensely-felt loss alongside the perceived continuation of a living relationship.

Mutuality of the relationship. The sense of the 'aliveness' of the bond that the senseof-presence experiences conveyed came across particularly in the emphasis on the interactive nature of the relationship:

'Someone was going through an old e-mail account and dug up an e-mail that [Kathy's deceased teacher] had sent her, saying 'I've just got off the phone with Kathy, and boy, do I love her!” And she copied and pasted just that [ ] and it was on a day when I had been thinking about her, so I think she was speaking through, I think she was still telling me she loved me [ ] and [ ] those kind of consolidate that it was a two-way thing.' (Kathy)

Once the ongoing connection had been confirmed through the sensing experience, further events could be interpreted as expressions of a living and interactive relationship. For many the mutuality involved a sense of the deceased communicating with them, sometimes explicitly, e.g. 'I heard her saying, "Don't worry about us."' (Nicholas), sometimes implicitly, e.g. 'she had forgiven me and she was somehow [ ] telling me this' (Harriet). Although these examples portrayed the deceased as the active message-giver and the bereaved as the passive message-receiver, there was an implication that the deceased was also aware of the feelings of the bereaved and responding to these.

The reported interactions sometimes involved the deceased as a higher spiritual being, similar to the asymmetrical relationships with saints in a religious context (Klass \& Goss, 1999), who can help the living but do not require help themselves. Sometimes the relationship also contained a symmetrical element:

'I just met a friend. [ ] We started chatting and I [told her] an anecdote about my father in a very loving way. I lost my father years and years ago [ ] but I had this strong 
tingling and I was really surprised. It was like my father had heard that and he was so excited that I had said that.' (Antonia)

Being able to affect the deceased loved one may be indicative of a more symmetrical relationship, similar to the co-dependency held to characterize relationships between the living and their ancestors in contexts such as Japan (Klass \& Goss 1999; Yamamoto et al., 1969). It entails a certain responsibility, expressed by Yvonne when saying about her husband's deceased daughter, 'She's happy, but she's got to be sad when she looks down and sees him when he's so sad'. Catrin also recounted that when receiving support from others following her husband's death, she felt how this affected her deceased husband:

'I could feel this incredible excitement on his part. And I was so happy for him. [ ] I was glad that he was relieved of his duty of watching me, looking over me, as it were, all the time. I was pleased for him that he was having a break.'

This quotation is not only an example of the perceived fluidity and mutuality of the relationship between the deceased and the bereaved; it also implies that other relationships could impact on the bond. This supports the suggestion by Klass (2006) that continuing relationships are embedded in a 'complex interactive web of bonds and meanings' (p. 846), pointing to the interrelationship between personal and social meanings.

Affirmation of self in relationship. Meaning-making in bereavement also tends to involve finding ways to reconstruct an identity which, being partly tied up with the deceased, has been challenged or shattered by the death. Many described sense-of-presence experiences as allowing them to maintain their identity in relation to the deceased. Antonia, who lost a son, expressed this vividly:

'I am a mother of two. It brings me back to that. I identify as a mother of two [ ] that's what I am [ ] I haven't lost that. I still am a mother of two and he's there.' 
For some, having had a sense-of-presence experience was in itself an affirmation of themselves and the relationship, as Kathy's example shows, as she felt boosted by sensing the presence of her apparently very popular teacher:

'It's helped my self-esteem a lot [ ] if someone like her, who was so loved and respected by thousands of people, would almost kind of bother to come and visit me postdeath, [ ] that I was worthwhile and seen and relevant.'

Feeling chosen by the deceased confirmed participants' self-worth and their identity in relation to the deceased. This function of presence-sensing was enhanced for those who reported having been given a particular message, as this could expand their identity in new and meaningful ways. Nicholas, for example, talked about the meaning of what his deceased mother had said to him:

'This voice was saying, “Don’t worry. Don’t worry about us. They're [Nicholas' deceased father and brother], they're grand," as my mother put it. "Your job now is to look after your brother and sister." That was [ ] the commission that had been given to me there.'

The sense-of-presence experience seemed to lead to a clear sense of purpose for Nicholas, although he also expressed feeling uncomfortable with being selected and how it might seem to his siblings ('Is this some sort of one-upmanship?') but, linking it with his identity as the one to maintain the family's faith tradition, the commission could be understood within a wider framework in terms of 'a sense of a living legacy'. The sensing experience thus not only played a central role in conveying the existence of a continuing bond but it tied the bond to identity-related meaningful tasks, both vis-à-vis the living and the dead, leading to self-affirmation as well as growth. Identity reconstruction in bereavement is often associated with personal or post-traumatic growth (Calhoun \& Tedeschi, 2006; Gillies \& Neimeyer, 2006) and it has been observed that identity change is most frequently reported to be existential in character (Matthews \& Marwit, 2006). This draws attention to the 
relevance of sense-of-presence experiences for meaning-making in terms of deeper understanding and purpose.

\section{Finding Meaning Through Existential, Spiritual, and Religious Sense-Making}

The accounts indicated not only the presence of meaning-making relating directly to the loss or absence of the deceased and the relationship with the deceased but also meaningmaking relating to 'global meaning in life' (Park, 2005) and 'transcendent values and ultimate concerns' (Paloutzian, 2005), particularly regarding the possibility of an afterlife.

Belief in life after death and death as temporary separation. The majority of participants reported making sense of the perceived presence of the deceased in terms of an afterlife. For many, the experience confirmed prior beliefs in this regard:

'It makes an experiential flavor to the kind of belief system I always had about there being life after death, like it was just a thing I read in books that I knew it was true, that kind of resonated with me [ ] And these experiences [have] given me some experiential, almost proof [ ] that the beliefs I have are real.' (Kathy)

Kathy stands for several participants when describing how the experience provided a sense of reality or 'evidence' that supported her previously more hypothetical or intuitive beliefs. Others said the experience led to a belief in an afterlife they had not had before but some also revealed an ongoing struggle with doubts:

'Up until then I had always been like, ah, didn't believe in the afterlife [ ] Once you go, you go, and that's it. I think there is something now. Yeah. Hm. Still a bit cynical but um I still think there's something. There is something.' (Elaine)

First Elaine professes that the experience led her to believe 'there is something now' but immediately thereafter her words indicate doubts and awareness of a different position, 
which she then argues against in the following sentence by asserting that she 'still' maintains that view. Elaine's example represents several participants' struggles with the discrepancy between the import of their felt experience and available conceptual frameworks. Another participant, Shirley, who identified herself as a non-believer, found that the experience gave her hope for an afterlife.

'It's hopefully a signal that this is how death really is. It may be a signal. It's trying to confirm something in me but I can't actually say that I'm totally convinced of it.'

In spite of Shirley's professed stance as non-believing, the experience seemed to link with existing internal meaning structures regarding the possibility of an afterlife. Although some participants spoke affirmatively of their belief that death was only a temporary separation, others were more tentative:

'I don't know for sure but based on experiences I've had and experiences my sisters have had [it] would seem to be the case, at least initially, that you get re-united with people, with family.' (Bridget)

In this sample, the perceived impact of sense-of-presence experiences on global meaning-making vis-à-vis belief in afterlife was thus varied and complex. Some participants were clearer when expressing their faith in the continued existence of their deceased loved ones than when expressing their faith in an afterlife:

'I could well imagine, maybe a few years later to be able to not believe in an afterlife but believing that my grandmother had one.' (Harriet)

While the situational meaning of sensing the presence of the grandmother was understood as an example of life after death, this did not translate automatically into a lasting global belief in an afterlife.

Existential insight and spiritual and religious meaningfulness. Most participants referred to the sense-of-presence experience using existential, spiritual and religious 
frameworks. Existential issues such as mortality and death anxiety were significant points of interest to many. Several participants spoke of being less afraid of death:

'I'd feel I'd go from being alive to being alive without carrying this body around me. And that's how I feel the sense of presences. If you lose the fear of death, which you could suppose to say that I have, it does make things seem a lot easier.' (Robert)

Reduced death anxiety and the yearning for reunion in death that survivors sometimes express can alarm professionals working with the bereaved, which might partly explain the lack of acceptance clients with sense-of-presence experiences have reported receiving from counselors (see Taylor, 2005). However, there was no indication in this sample that the experience inspired a longing for death. Rather, it was reported to help bridge the gap between this life and a hereafter:

'I need [son's] presence [ ] because [if] I don't have that, how am I going to survive the thought of having another forty years before I see them?' (Antonia)

What seemed to be important for most participants was that their existential sensemaking was tied in with spiritual or religious frameworks which offered them a sense of meaningfulness above and beyond a belief in an afterlife:

'I don't think [the deceased teacher] is my personal guide. I probably think she's someone that, don't know, floats around occasionally to come and help or something [ ] and I suppose that helps me to think that she's still got a purpose and still has a place in the universe.' (Kathy)

Kathy, who had wondered how her teacher/mentor could be 'taken' at such an early age, thus felt reassured that there was some meaning in her death. Experiencing the deceased as fulfilling a meaningful spiritual role links this theme with the above-mentioned sub-theme of 'viewing the deceased as a spiritual being and resource' and thus shows a connection between gaining personal benefit and finding spiritual meaning. Sense-of-presence 
experiences could then also be seen as divine acts of goodness or 'gifts from God' (Antonia), suggesting that the availability of religious and spiritual frameworks was important for the integration of sense-of-presence experiences beyond immediate coping concerns.

Spiritual and religious growth. Some participants talked about how the experience brought existing religious conflicts and questions more keenly to awareness. For example, Shirley, who had lost her faith in God following several traumatic losses in her life, said:

'I did believe that the soul must go somewhere [ ] but where exactly I don't know. I just can't believe that this mechanism of ours, this body, is just all for nothing. What it is, who it is, where it is, I still don't know.'

Shirley uses the past tense when speaking about her belief in an afterlife, suggesting that she no longer holds this belief. Her questions indicate that she is troubled by the discrepancies within her meaning system and her 'still' not knowing suggests that she is motivated to address those questions. Spiritual and religious growth is believed to result from a spiritual struggle in response to a challenged belief system that triggers a 'search for meaning' (Balk, 1999; Landsman, 2002). For some participants, the sense-of-presence experience was said to have inspired a spiritual journey and led to spiritual transformation:

'It's very easy to stay in your belief system and not challenge yourself. It's very easy just to [say] "There is no more life after death." That's just too easy. It's more difficult to challenge yourself to explore, to rethink. So for me I think this experience [ ] opened up a door that may have otherwise just stayed completely shut and I would still be the person that thought, "That's it. Game over. There is no spirituality. There is no connection with anybody.", (Tanya)

Tanya emphasizes that changing one's global meaning system is not easy. This links with observations made above about the possible impact of such experiences on global meaning as complex and varied. Sense-of-presence experiences not only challenged those 
who held no prior belief in an afterlife, but also and particularly some of those who identified as committed Christians and who found the experience in conflict with church teachings. Antonia tried to reconcile sensing the presence of her son with her church's insistence that he had moved on:

'[He] is with God. I think they say he's with God but to me God and the spiritual world could very well be with us. We don't know if it's here and there. We cannot tell, you know, so I don't see that. We don't know how it is.'

As Antonia and indeed a few others expressed, spiritual growth following the senseof-presence experiences could involve an acceptance of mystery and of not having all the answers. However, this did not mean that the hope for an ultimate revelation of meaning needed to be forsaken. As Catrin put it:

'I feel that there is a reason. [ ] I love the image of the carpet that's woven and in this life, on this side, we see the back with all the loose ends, you know, all the bits, and then when we get to the other side, we see this beautiful finished thing.'

\section{Discussion}

With its emphasis on subjective experience and meaning making, the goal of this qualitative study was not to test hypotheses but to gain in-depth understandings of subjective processes reported by a small, specific set of participants.. As all participants were White, most were female and no major faith tradition apart from Christianity was represented, a range of possibly significant perspectives could not be examined here. However, participants differed in terms of age, spirituality/religiosity and the kinds of losses and sense-of-presence experiences they reported, suggesting that commonalities in the data could allow insight into issues and themes that are of broader relevance to the processes under discussion. The 
transferability of the findings to other groups and contexts needs to be determined through further research.

Considering the well-documented reluctance to disclose such experiences due to perceived conflicts with dominant paradigms (Hay \& Heald, 1987), the sample may have been biased towards those with better access to relevant socially sanctioned conceptual frameworks. However, the discerned themes on conceptual discrepancies and social nonacceptance suggest that participants also experienced such conflicts. There may also have been a self-selection bias towards more positive sensing experiences in this sample. Those with more distressing experiences may perhaps have been less likely to volunteer to take part in a lengthy interview which required them to re-engage with those experiences. Although negative sense-of-presence experiences are not as frequently reported as positive ones in nonclinical samples, they do occur and merit attention in their own right (for an interesting example, see Parker, 2005).

'Benefit-finding' as a component process of meaning reconstruction in bereavement (Gillies \& Neimeyer, 2006) emerged as linked with the feeling that the loss was partially reversed or reduced. This constituted a sense of 'presence in absence' rather than a denial of death or 'unresolved loss' (Field, 2006) and was described as a source of solace as well as practical and spiritual support.

The majority of participants seemed to find benefit in the continuing bond with the deceased and talked about an interactive and mutual relationship in the here and now rather than a relationship in which the other was 'held as a "frozen" entity in the psyche' (Silverman \& Klass, 1996, p. 19). This theme also indicated partly 'symmetrical' relationships, similar to the co-dependency of ancestral bonds in cultures such as Japan (Klass \& Goss, 1999). This was an unusual finding, as continuing bonds in the West have been regarded as 
'asymmetrical', as in bonds with 'the sacred dead' (Klass \& Goss, 1999). The continuing bond also served as a source of self-definition and self-worth for many, restoring their identity within the relationship with the deceased and in some cases giving rise to new identity-related meaning, which concurred with the meaning reconstruction component of 'identity change' and underpinned Conant's (1996) finding about the benefit of sensing experiences for the survivors' sense of self.

While 'finding meaning' in terms of deeper understanding and purpose could also be discerned as a theme across accounts, there was considerable variation between participants. While all participants interpreted the experience as relating to an afterlife, which gave them hope for a reunion with the deceased and helped reduce death anxiety, several participants remained doubtful, indicating a discrepancy between their situational and global beliefs, in contrast to Benore and Park's (2004) suggestion that a global belief in an afterlife may be a pre-requisite to a belief in the continuing attachment with the deceased. Participants for whom spirituality/religion was 'extremely important' reported no discrepancies here, which suggests that the availability of spiritual and religious conceptualizations facilitated the meaningful integration of the experience into their assumptive worldview, confirming the importance of meaning-making in connection with continuing bonds as suggested by Neimeyer, Baldwin and Gillies (2006). However, spiritual and existential discrepancies were also reported to lead to a (continued) 'search for meaning', a 'spiritual journey' and 'spiritual transformation', and discrepancies were experienced by some of the committed Christians in the sample, who had to find ways of resolving their dilemma that sense-of-presence experiences seemed to be in conflict with religious doctrine.

Thus, while participants readily found benefit in the partial reversal of their loss and the continuing bond with the deceased, the impact of sense-of-presence experiences on global meaning-making was less straightforward, sometimes involving an ongoing search for 
meaning as well as the possibility of post-traumatic growth (Calhoun \& Tedeschi, 2006). This conclusion concurs with Davis' (2008) argument in favor of a distinction between 'growth' and 'benefits'. It seemed that benefits could be found even in the light of discrepant global meaning systems. However, growth seemed to require the availability of spiritual and religious frameworks which could be adopted or accommodated for the meaningful integration of the experience.

Owing to the size and specificity of the sample, the present study's finding of positive value being attributed to sense-of-presence experiences should not be seen as making claims about the nature and implications of sense-of-presence experiences per se. Neither should it be seen as undermining claims advanced by studies of greater scope that have yielded different findings with large samples (e.g. Field and Filanosky’s, 2010, finding that clear sensory perceptions of the deceased were associated with two known risk factors for complicated grief). However, the present study does serve to illustrate findings of a recent mixed-methods study by Lichtenthal, Currier, Neimeyer, and Keesee (2010), which showed that spiritual sense-making and benefit-finding in bereavement ranked highly as predictors of better adjustment, thus providing support for the adaptiveness of spiritual sense-making. While Lichtenthal et al. did not look at sense-of-presence experiences and other continuing bonds expressions, Neimeyer et al. (20006) found that continuing bonds are most adaptive when the bereaved can make sense of their loss, and it could be tentatively concluded that doing so in spiritual terms following profound senses of contact and connection can advance this goal. As regards further research and theory development, the finding that, in the present study, ongoing relationships can be experienced as 'symmetrical' in a Western context also merits further exploration from a more socio-culturally oriented continuing bonds perspective. What implications might it have for the bereaved to feel they can still affect the deceased, especially in a society that views any post-death contact with great skepticism? For 
example, how do the bereaved experience and perform their perceived responsibilities vis-àvis the deceased outside clearly delineated and demarcated religious frameworks? The role of existing spiritual/religious conceptual frameworks with regard to sense-of-presence experiences needs to be further elucidated. For example, how are discrepancies between such phenomena and non-Christian meaning systems experienced and negotiated? Further attention should be given to the (growth) processes by which discrepancies between situational and global meaning-making are resolved (or by which resolution is hindered), in particular with regard to the role of culturally available conceptual frameworks.

As regards implications for practice, several recommendations can be made. As mentioned earlier, counseling and psychotherapy are often the only places in which postbereavement meaning-making processes are actively engaged. The importance of creating a safe space for exploring sensitive issues is heightened in the case of sense-of-presence experiences due to people's reluctance to disclose such phenomena. While these experiences may often be benign and could be seen as belonging to the more positive consequences of bereavement (see Stroebe \& Schut, 2001) that could be validated by practitioners as helpful and meaningful to the bereaved, particularly if they can serve spiritual meaning-making (Lichtenthal et al., 2010; Neimeyer et al., 2006), it needs to be acknowledged that negative experiences do happen and that practitioners may need to sensitively explore the meanings such an event may have for the bereaved, for example in terms of 'unfinished business' in the relationship with the deceased (Parker, 2005; Tyson-Rawson, 1996) as well as any anxieties triggered by the experience (LaGrand, 1997). The importance of showing respect, (cultural) sensitivity, empathy and acceptance when dealing with this phenomenon (LaGrand, 1997; Taylor, 2005; Tedeschi \& Calhoun, 2006) is reiterated for any scenario. To facilitate the integration of sense-of-presence experiences into clients' global meaning systems or assumptive worldviews and foster growth, therapists may need to address the potential lack 
of conceptual frameworks and be prepared to explore the spiritual and religious dimensions of these experiences. This may not only require openness and sensitivity as well as knowledge of different belief systems, but practitioners may also need to reflect on their own (lack of) beliefs and become 'companions on the journey' alongside the bereaved (Tedeschi \& Calhoun, 2006, p. 112).

\section{References}

Balk, D.E. (1999). Bereavement and spiritual change. Death Studies, 23, 485-493.

Becker, G., Xander, C.J., Blum, H.E., Lutterbach, J., Momm, F., Gysels, M., \& Higginson, I.J. (2007). Do religious or spiritual beliefs influence bereavement? A systematic review. Palliative Medicine, 21, 207-217.

Bennett, G., \& Bennett, K.M. (2000). The presence of the dead: An empirical study. Mortality, 5,139-157.

Benore, E.R., \& Park, C.L (2004). Death-specific religious beliefs and bereavement: Belief in an afterlife and continued attachment. The International Journal for the Psychology of Religion, 14, 1-22.

Bowlby, J. (1998), Attachment and loss (Vol. 3). Loss: Sadness and depression. London: Pimlico.

Braun, V., \& Clarke, V. (2006). Using thematic analysis in psychology. Qualitative Research in Psychology, 3, 77-101.

Calhoun, L.G., \& Tedeschi, R.G. (Eds.). (2006). Handbook of posttraumatic growth: Research and practice. Mahwah, NJ: Lawrence Erlbaum Associates.

Conant, R.D. (1996). Memories of the death and the life of a spouse: The role of images and sense of presence in grief. In D. Klass, P.R. Silverman, \& S. Nickman, S. (Eds.), 
Continuing bonds: New understandings of grief (pp. 179-196). Bristol, UK: Taylor \& Francis.

Chan, C.L., Chow, A.Y., Ho, S.M., Tsui, Y.K., Tin, A.F., Koo, G.W., \& Koo, E.W. (2005). The experience of Chinese bereaved persons: A preliminary study of meaning making and continuing bonds. Death Studies, 29, 923-947.

Datson, S.L., \& Marwit, S.J. (1997). Personality constructs and perceived presence of deceased loved ones. Death Studies, 21, 131-146.

Davis, C.G. (2008). Redefining goals and redefining self: A close look at posttraumatic growth following loss. In: M.S. Stroebe, R.O. Hansson, H. Schut, \& W. Stroebe (Eds.), Handbook of bereavement research and practice: Advances in theory and intervention (pp. 309-325). Washington DC: American Psychological Association.

Davis, C.G., Nolen-Hoeksema, S., \& Larson, J. (1998). Making sense of loss and benefiting from the experience: Two construals of meaning. Journal of Personality and Social Psychology, 75, 561-574.

Elliott, R., Fischer, C.T., \& Rennie, D.L. (1999). Evolving guidelines for publication of qualitative research studies in psychology and related fields. British Journal of Clinical Psychology, 38, 215-229.

Epstein, R., Kalusz, C., \& Berger, M. (2006). The continuing bond oft he bereaved towards the deceased and adjustment to loss. Mortality, 11, 254-268.

Field, N.P. (2006). Unresolved grief and continuing bonds: An attachment perspective. Death Studies, 30, 739-756.

Field, N.P. (2008). Whether to relinquish or maintain a bond with the deceased. In: M.S. Stroebe, R.O. Hansson, H. Schut, \& W. Stroebe (Eds.), Handbook of bereavement research and practice: Advances in theory and intervention (pp. 113-132). Washington DC: American Psychological Association. 
Field, N.P., \& Filanosky, C. (2010). Continuing bonds, risk factors for complicated grief, and adjustment to bereavement. Death Studies, 34, 1-29.

Folkman, S. (2001). Revised coping theory and the process of bereavement. In M.S. Stroebe, W. Stroebe, R.O. Hansson, \& H. Schut, (Eds.), Handbook of bereavement research: Consequences, coping and care (pp. 563-584). Washington DC: American Psychological Association.

Frankl, V.E. (1959). Man's search for meaning. New York: Pocket Books.

Freud, S. (1917). Mourning and melancholia. In J. Strachey (Ed. and Trans.), The standard edition of the complete psychological works of Sigmund Freud (Vol. XIV) (pp. 252268). London: Hogarth Press.

Gillies, J., \& Neimeyer, R.A. (2006). Loss, grief, and the search for significance: Toward a model of meaning reconstruction in bereavement. Journal of Constructivist Psychology, 19, 31-65.

Golsworthy, R., \& Coyle, A. (1999). Spiritual beliefs and the search for meaning among older adults following partner loss. Mortality, 4, 21-40.

Goss, R.E., \& Klass, D. (2005). Dead but not lost: Grief narratives in religious traditions. Walnut Creek, CA: Altamira.

Grimby, A. (1998). Hallucinations following the loss of a spouse: Common and normal events among the elderly. Journal of Clinical Geropsychology, 4, 65-74.

Hay, D., \& Heald, G. (1987, April 17). Religion is good for you. New Society, pp. 21-22. Janoff-Bulman, R. (1992). Shattered assumptions: Towards a new psychology of trauma. New York: The Free Press.

Klass, D. (2006). Continuing conversation about continuing bonds. Death Studies, 30, 843858. 
Klass, D., \& Goss, R. (1999). Spiritual bonds to the dead in cross-cultural and historical perspective: Comparative religion and modern grief. Death Studies, 23, 547-567.

Klass, D., Silverman, P.R., \& Nickman, S. (Eds.). (1996), Continuing bonds: New understandings of grief. Bristol, UK: Taylor \& Francis.

LaGrand, L.E. (1997). After death communication: Final farewells. St. Paul, MN: Llewellyn Publications.

Lalande, K.M., \& Bonanno, G.A. (2006). Culture and continuing bonds: A prospective comparison of bereavement in the United States and the People's Republic of China. Death Studies, 30, 303-324.

Lichtenthal, W.G.; Currier, J.M.; Neimeyer, R.A.; \& Keesee, N.J. (2010). Sense and significance: A mixed methods examination of meaning making after the loss of one's child. Journal of Clinical Psychology, 66, 791-812.

Lindemann, E. (1944). The symptomatology and management of acute grief. American Journal of Psychiatry, 101, 141-148.

Lindstrom, T.C. (1995). Experiencing the presence of the dead: Discrepancies in the 'sensing experience' and their psychological concomitants. Omega: Journal of Death \& Dying, $31,11-21$.

Madill, A. Jordan, A., \& Shirley, C. (2000). Objectivity and reliability in qualitative analysis: Realist, contextualist and radical constructionist epistemologies. British Journal of Psychology, 91, 1-20.

Matthews, L.T., \& Marwit, S.J. (2006). Meaning reconstruction in the context of religious coping: Rebuilding the shattered assumptive world. Omega: Journal of Death and Dying, 53, 87-104. 
Neimeyer, R.A. (2001). The language of loss: Grief therapy as a process of meaning reconstruction. In R.A. Neimeyer (Ed.), Meaning reconstruction and the experience of loss (pp. 261-292). Washington, DC: American Psychological Association.

Neimeyer, R.A. (2006). Complicated grief and the reconstruction of meaning: Conceptual and empirical contributions to a cognitive-constructivist model. Clinical Psychology: Science and Practice, 13, 141-145.

Neimeyer, R.A., Baldwin, S.A., \& Gillies, J. (2006). Continuing bonds and reconstructing meaning: Mitigating complications in bereavement. Death Studies, 30, 715-738.

Paloutzian, R.F. (2005). Religious conversion and spiritual transformation: A meaningsystem analysis. In R.F. Paloutzian, \& C.L. Park (Eds.), Handbook of the psychology of religion and spirituality (pp. 331-347). New York: Guildford Press.

Park, C.L. (2005). Religion and meaning. In R.F. Paloutzian, \& C.L. Park (Eds.), Handbook of the psychology of religion and spirituality (pp. 295-314). New York: Guildford Press.

Parker, J.S. (2005). Extraordinary experiences of the bereaved and adaptive outcomes of grief. Omega: Journal of Death and Dying, 51, 257-283.

Parkes, C.M. (1970). The first year of bereavement. Psychiatry: Journal for the Study of Interpersonal Processes, 33, 444-467.

Parkes, C.M. (1996). Bereavement: Studies of grief in adult life $\left(3^{\text {rd }}\right.$ ed.). London: Penguin.

Rees, D. (1971). The hallucinations of widowhood. British Medical Journal, 4, 37-41.

Rees, D. (2001). Death and bereavement: The psychological, religious and cultural interfaces (2nd ed.). London: Whurr.

Richards, T.A., Acree, M., \& Folkman, S. (1999). Spiritual aspects of loss among partners of men with AIDS: Postbereavement follow-up. Death Studies, 23, 105-127. 
Rosenblatt, P.C. (1997). Grief in small-scale societies. In C.M. Parkes, P. Laungani, P., \& B. Young (Eds.), Death and bereavement across cultures (pp. 27-51). London: Routledge. Sanger, M. (2009). When clients sense the presence of loved ones who have died. Omega: Journal of Death \& Dying, 59, 69-89.

Silverman, P.R., \& Klass, D. (1996). Introduction: What's the problem? In D. Klass, P.R. Silverman, \& L. Nickman (Eds.), Continuing bonds: New understandings of grief (pp. 3-27). Bristol, UK: Taylor \& Francis.

Simon-Buller, S., Christopherson, V.A., \& Jones, R.A. (1988-89). Correlates of sensing the presence of a deceased spouse. Omega: Journal of Death and Dying, 19, 21-30.

Sormanti, M., \& August, J. (1997). Parental bereavement: Spiritual connections with deceased children. American Journal of Orthopsychiatry, 61, 460-469.

Steffen, E., \& Coyle, A. (2010). Can 'sense of presence' experiences in bereavement be conceptualised as spiritual phenomena? Mental Health, Religion and Culture, 13, 273291.

Stroebe, M., Gergen, M., Gergen, K., \& Stroebe, W. (1996). Broken hearts or broken bonds? In D. Klass, P.R. Silverman, \& S. Nickman (Eds.), Continuing bonds: New understandings of grief (pp. 31-44). Bristol, UK: Taylor \& Francis.

Stroebe, M.S., \& Schut, H. (2001). Meaning making in the dual process model of coping with bereavement. In R.A. Neimeyer (Ed.), Meaning reconstruction and the experience of loss (pp. 55-73). Washington DC: American Psychological Association.

Stroebe, M.S., Schut, H., \& Stroebe, W. (2005). Attachment in coping with bereavement: A theoretical integration. Review of General Psychology, 9, 48-66.

Taylor, S.F. (2005). Between the idea and the reality: A study of the counseling experience of bereaved people who sense the presence of the deceased. Counselling and Psychotherapy Research, 5, 53-61. 
Tedeschi, R.G., \& Calhoun, L.G. (2006). Time of change? The spiritual challenges of bereavement and loss. Omega: Journal of Death and Dying, 53, 105-116.

Tyson-Rawson, K. (1996). Relationship and heritage: Manifestations of ongoing attachment following father death. In D. Klass, P.R. Silverman, \& S. Nickman (Eds.), Continuing bonds: New understandings of grief (pp. 125-145). Bristol: UK: Taylor \& Francis.

Walter, T. (1999). On bereavement: The culture of grief. Buckingham, UK: Open University Press.

Walter, T. (2002). Spirituality in palliative care: Opportunity or burden? Palliative Medicine, $16,133-139$.

Wortman, C.B., \& Silver, R.C. (1989). The myths of coping with loss. Journal of Consulting and Clinical Psychology, 57, 349-357.

Wortman, J.H., \& Park, C.L. (2008). Religion and spirituality in adjustment following bereavement: An integrative review. Death Studies, 32, 703-736.

Yamamoto, J., Okonogi, K., Iwasaki, T., \& Yoshimura, S. (1969). Mourning in Japan. American Journal of Psychiatry, 125, 1660-1665.

Yardley, L. (2000). Dilemmas in qualitative health research. Psychology and Health, 15, 215228.

\footnotetext{
${ }^{1}$ This may be a surprising statement to readers unfamiliar with the wariness of some religious groups and traditions about any ongoing contact with (or attempt to contact) those who have died, given the super-natural focus of religion and spirituality. Nevertheless, the borders between (attempted/perceived) contact with the dead and sorcery are blurred within some religious traditions.
} 